\title{
Formative Assessment in Higher Education: From Theory to Practice
}

\author{
Rudīte Koka \\ Rīga Stradiņš University \\ Anžela Jurāne-Brēmane \\ Vidzeme University of Applied Sciences \\ Tatjana Kokse \\ Rīga Stradinsš University
}

\begin{abstract}
The aim of the research is to emphasize the practical implementation of the formative assessment. The research leads to the conclusion that lecturers implement the findings of different theories and researches on formative assessment rather slowly in their daily work and practice. This article shows the way from theory to practice in the study course Human molecular biology at Rīga Stradinš University. Quantitative and qualitative data collection methods are used to research the influence of formative assessment both on individual and institutional levels. The results show the importance of feedback information both for lecturer and student. It is concluded that immediate feedback is important for the improvement of student's achievements. The road towards initiating formative assessment on institutional level has been outlined.
\end{abstract}

Keywords: feedback, formative assessment, higher education.

\section{Introduction}

A contemporary study process is seen as interaction based on the relationship between lecturers, students and content of the studies, where lecturer and student are equal partners. Some serious questions arise: how the lecturer should organize the study process in order to promote student learning; how students can guide their own learning, how to get feedback in this process? Centre for Educational Growth organized further education seminars for Rīga Stradiņš University lecturers about actualities of formative assessment within the 2014/2015 academic year. In those seminars theoretical concepts of formative assessment and learning theories (Vygotsky, Black, Wiliam, Fullan, Colby-Kelly, Turner, Shute, Falchikov, Race, Irons) were discussed. Importance of the feedback and feed-forward was emphasized as well as self-assessment and peer-assessment, shift of the assessment culture was analysed. The experience from those seminars encouraged more precise formation of examples of formative assessment both for lectures and practical workshops within the 2015/2016 academic year.

\section{The study aim}

The study aim is to approbate created formative assessment examples in the lectures and practical workshops of the study course Human molecular biology through the available technologies in the department, such as voting consoles, interactive whiteboard. In this study qualitative and quantitative data collection methods are used: questionnaires for students and lecturers, structured pedagogical observation, focus group discussion. 


\section{To find a place for formative assessment}

Formative assessment has positive impact on student's achievements (Black, \& Wiliam, 2009; Furtak, Kiemer, Circi, Swanson, de Leon, Morrison, \& Heredia, 2016). J. Hattie characterizes feedback as information about aspects of one's performance or understanding and consequence of performance (Hattie, 2009). Researchers emphasize importance of feed-forward that provides guidance for improvements in future activities and it is important for students and lecturers (Frey, Fisher, 2011; Wheatley, Mclnch, 2015). Formative assessment through feedback and feed-forward promotes learning.

P. Black and D. Wiliam in their early publications on formative assessment name five most important types of activities identified from the evidence on the potential effectiveness: to acquaint students with the criteria of achievement; to question during the lessons; to do assessment only with comments; to introduce self-assessment and peer-assessment; summative use of formative tests. Subsequent activities also prove exactly how they correspond with formative assessment concept (Black, \& Wiliam, 2009). The authors' approach suggests that any evidence on formative interaction should be analyzed by reflecting on lecturer's chosen plan to develop student learning.

Pedagogy is effective when teaching activities focus on participation, for example, questioning, feedback on the responses and actions, and developing special forms of dialogue between lecturers and students as well as between students (Ecclestone, Davies, 2010). D. R. Sadler characterizes new doctrines by emphasizing the meaning of feedback in the study process (Sadler, 1998). I. Clark uses the term "formative learning environment", in which, as demonstrated by the research, the student is actively involved and is protected from academic failure (Clark, 2014). Prior to that, P. Black and D. Wiliam point out that teacher is responsible for the establishment and implementation of an effective learning environment while student is responsible for learning in this environment. Consequently, both the lecturer's and the student's responsibility is to do everything possible to minimize the impact of any failures, it is common liability (Black, Wiliam, 2009).

P. Black recommends to allocate more time for questioning and answering (two sided) so that less confident students have time to respond or ask questions. Student involvement initially can be increased by asking to discuss the ideas in pairs. Questioning becomes an important part of teaching in order to promote learning. Questioning from the lecturer without grades promotes student activity and awareness that learning is promoted rather by the ability to discuss their knowledge than the ability to answer questions more accurately (Black, 2003). Responsibility of the lecturer is preparation of quality questions that are designed to explore and challenge common misunderstandings as well as encouraging students to resolve mistakes together, reaching answers in cooperation (Black, Harrison, Lee, Marshall, \& William, 2003).

S. Bloxham and P. Boyd, writing on effective assessment in higher education, describe formative assessment as valuable for students to monitor their progress and identify difficulties, but it may be a considerable force, if it provides information to the lecturer about the teaching work. It is important to change the teaching plans in response to information about student learning, and this information can come from the most diverse sources: the students' questions, exercises in class. More information on student progress increases the lecturer's chance to help them (Bloxham, Boyd, 2007). Summarizing research on assessment for learning, K. Sambell points out several recommendations: complex learning advances, when feedback is seen as interrelated process, is dialogical and is integral throughout the teaching and learning process (Sambell, 2011). Formative assessment is not a fixed process with a single formula, but a set of ways how lecturers can find out the information about what students know and can do, and then this information is useful both for feedback to students and future lesson planning (Black, Harrison, Lee, Marshall, \& Wiliam, 2003).

There must be a place for formative assessment in the study programs, by reducing formal lectures, where students are not actively involved in the learning process. Another option is to make wider use of rapidly developing information and communication technologies, for example, automated testing with immediate feedback (Yorke, 2003; Nicol, \& MacfarlaneDick, 2006; Nicol, D. J., \& Milligan, C. 2006). K. D. McConnell and P. E. Doolittle emphasize voting consoles as one of the technology-supported techniques pointing out that it helps students to assess their knowledge anonymously (McConnell, \& Doolittle, 2011). 


\section{Research design, procedure and results}

With the aim to find out formative assessment practices in everyday pedagogical process at Rīga Stradinš̌ University during the academic year 2015/2016, research was implemented in first year study course "Human molecular biology" in Dentistry faculty. The study course is performed in Latvian and English languages, 53 students acquire this course, and it is carried out by two lecturers, one of them works only with international students conducting lectures in English, while the other lecturer works with Latvian students. For this research the group of students who acquired course in Latvian was selected because lecturer was interested in starting a formative assessment in the study process while the other lecturer intends to start it next academic year if the result is successful. Thus, the selected group constitutes an experimental group of 22 students, who acquired the study course Human molecular biology in Latvian. The control group was not created deliberately because the research was not intended to measure the correlation between students' achievements in summative and formative assessment. It is a well known fact as evidenced by theoretical conclusions of other scientists (Yorke, 2003; Nicol, \& Macfarlane-Dick, 2006; Black, \& Wiliam, 2009).

The lecturer created diverse and relevant to content 8-10 formative assessment tasks for each lecture and workshop before the beginning of formative assessment. The classification matrix of the tasks was set in order they meet the criteria (diversity and relevance to content). The study results to be achieved and task division according to level of cognitive activity was taken into account while creating the tasks (elementary algorithm task and problem-task) as well as task division according to type of response (short answer tasks, structured essay tasks), task division according to type of implementation (in writing, orally, electronically executed through voting consoles) (Table 1).

\section{Table1. An example of the task classification matrix.}

\begin{tabular}{|l|l|l|}
\hline Topic No 1 & Task classification & Task classification \\
\hline $\begin{array}{l}\text { Lecture } \begin{array}{l}\text { Classical genetics } \\
\text { basics }\end{array} \\
\text { Problem-task: Structured task and essay type, for example: } \\
\text { to explain the process } \\
\text { to assess the claim } \\
\text { to make a definition } \\
\text { to formulate conclusions }\end{array}$ & 4 writing/4oral; \\
\hline $\begin{array}{l}\text { Practical lesson } \\
\text { Classical genetics } \\
\text { basics }\end{array}$ & $\begin{array}{l}\text { Elementary algorithm task: } \\
\text { for example: test (multiple choice) and short answer } \\
\text { (yes/no) and others voting system task }\end{array}$ & use the voting system \\
\hline
\end{tabular}

The questionnaire was created for the students to assess whether the tasks examine the substantive content, and whether the tasks are diverse. All (22) students of the experimental group filled in the questionnaire at the end of the study course. The questionnaire included only open-type questions and the results obtained were processed in a standard way using Microsoft Excel, grouping by similar and different features, as a result the categories were established.

Structured pedagogical observation protocol was created and other lecturers were invited to participate in lectures and practical workshops in order to get not only the students' point of view, but also professionals' view. Observation was held 12 times during the study course, and generally engaged 12 lecturers, which by specialization could be classified as follows: six lecturers of department working with similar content and can later use formative assessment in their pedagogical activity; two professionals of information technology who examined the applications of information technology as well as provided valuable advice to the best use of voting consoles and interactive whiteboard; three representatives of administration that from the results obtained could contribute to the promotion of formative assessment approaches on a wider level of Riga Stradinš University; and one lecturer from another university, who examined the meaningful application of pedagogical causalities of formative assessment in practice. The observation protocol was structured by three criteria: 
student's activity at the lecture or workshop, indicating her/his involvement in the formative assessment on the merits (for example, students are not passive listeners, but active participants in the study process: they ask if they do not understand, they justified their answers, analyzing their mistakes, not afraid to make mistakes, etc. );

lecturer's activity giving evidence of meaningful application of formative assessment in the study process (for example, does not ignore the students' doubts, misunderstandings; responding to students' questions, even provoke them, challenges students to prove their answers; provide feedback immediately; encourages students to think, analyze, etc. );

use of information technology indicating the meaningful application (for example, using the voting consoles for gaining immediate feedback, using interactive whiteboard features for the best explanation etc. ).

During the observation lecturers filled the protocol with evidence or confirmations according to the criteria. Lecturer involved in this study and the observer analyzed the accumulated information at the lecture or practical workshop after each observation. The results of structured pedagogical observation were processed in a standard way using Microsoft Excel, grouping by similar and different features, as a result the categories were established. At the end of the study course focus group discussion was organized for the students of experimental group with the aim to find out their key benefits when formative assessment is going on at lectures and workshops, and students gain immediate feedback as well as whether the students also applied acquired skills in other study course. The focus group discussion transcription and establishing of the categories was done after data collection. The following categories of the competences were obtained by analysing and comparing results of student surveys and focus group discussions (Table 2).

\section{Table 2. Categories of the student's skills due to formative assessment.}

\begin{tabular}{|c|c|}
\hline Category & Evidence obtained in the focus group discussion \\
\hline students develop the self-control skills & $\begin{array}{l}\text {.. easy to control oneself; } \\
\text {.. I can quickly find out whether it is understood; } \\
\text {.. I find out own mistakes immediately; } \\
\text {.. better to make a mistake in a lecture than a colloquium; } \\
\text {.. work for myself }\end{array}$ \\
\hline students develop the communication skills & $\begin{array}{l}\text {.. for me it is useful that we can mutually discuss the task; } \\
\text {.. the most difficult is to tell in your own words }\end{array}$ \\
\hline students develop collaboration skills & $\begin{array}{l}\text {.. it is a good opportunity to learn together; } \\
\text {.. the best tasks were working in pairs because one does not } \\
\text { feel safe about understanding }\end{array}$ \\
\hline students develop the skills of solving different types of tasks & $\begin{array}{l}\text {.. I like to create small summaries; } \\
. . \text { helps when at the end of the lecture are questions about what } \\
\text { was at the beginning of lecture; } \\
\text {.. I like the tasks, where should be arranged sequentially one } \\
\text { process; } \\
\text {.. multiple choice tasks are helpfull }\end{array}$ \\
\hline $\begin{array}{l}\text { students develop the skills of perception and memory } \\
\text { improvement }\end{array}$ & $\begin{array}{l}\text {.. usually my attention is for } 45 \text { minutes, but now I am involved } \\
\text { all time of lecture - } 90 \text { minutes; } \\
\text {.. really it is, when I go to a lecture, then I do understand.. all } \\
\text { and then in the workshop it is easy to remember and } \\
\text { understand; } \\
\text {... start thinking }\end{array}$ \\
\hline students are active participants in the process & $\begin{array}{l}\text {.. I feel engaged the whole lecture period; } \\
\text {.. acquiring content completely during the lecture; } \\
\text {.. sometimes the theory seems so "abstract" and it is difficult to } \\
\text { understand hoe to use it, but if there is a task during lecture, } \\
\text { then immediately it is clear why tho learn it; } \\
\text {.. all the time I have been toned; } \\
\text {.. no possibility to sleep, relax; } \\
. . \text { I can see my progress }\end{array}$ \\
\hline
\end{tabular}


Students also gladly recommend improvements for the formative assessment tasks during lectures and practical workshops, like ".. even more and more difficult tasks... ". ".. insert the tasks in e-learning environment for solving them at home.. ", ".. questions more specifically differentiate from easiest to hardest.. ". Students' opinions help lecturers to improve their work, it is double-sided and meaningful feedback. This data confirms the theoretical conclusions in pedagogy (Yorke, 2003; Bloxham, \& Boyd, 2007; Clark, 2014), that in case formative assessment is organized purposefully and student involvement occurs essentially, then self reflection and communication are all important features of a student's employability and will be invaluable to them throughout their lives. Transfer of acquired skills to other situations is one of the most important basic conditions for formative assessment, therefore it was essential to inquire in focus group discussion whether students applied the acquired skills in other study courses. The discussion in focus group serves as evidence: "... I began to think similarly in other subjects, such as histology... ", "... it helped me when I learned about tooth eruption, grooves... ", "... while in another lecture, I began to think, as I wanted to check myself... ". Of course, there are also students' recommendations: "... I would want such learning in other study courses". This is a serious challenge for university lecturers in general. Students also discovered their view: "... I do not want to be a passive listener... ".

The following categories were obtained in analyzing the lecturers completed protocols of structured pedagogical observation:

the compliance of formative assessment tasks with the essential content of the course;

the student involvement;

the effect of the feedback;

the use of information technology.

The first category was most accurately assessed by the lecturers who work with similar content. Their observed and fixed comments evidenced, for example: "... the questions raised examined the most important topics... ", "... questions help students easily perceive the contents of genetics... ", "... regular and varied tasks of the lecture... ", "... the task set is effective, because the tricky answers are covered in multiple-choice tasks", "... the created material is innovative, it is placed in the RSU (Rīga Stradinš University) e-learning environment and available to every lecturer as a successful model... ", "... transfer and adaptation of the model established in other study courses should be promoted... ."

Whereas on observation of students' work the records of observation protocols confirm that student involvement is essential rather than formal: "...students participated actively and looked motivated. They focused on the class subjects to understand deeply... ", "...students are ready to comment on why given the exact answer... ", "... comments themselves, why is it wrong... ", "... the unclear issues were immediately discussed... ", "...are able to get each student's answer.. "

A few extracts from the lecturer's observation protocols as evidence of the feedback immediate effect: "... at the lecture feedback is being continuously obtained on the students' understanding...., "... lecturer explained all subjects very nicely and explanation was easily understandable. Talking speed is also good. Taking care of all students equally and individually... ", "... continuous involvement of the students by asking questions and asking to continue the sentence".

Lecturers and information technology professionals also observed the effectiveness of information technology usage: are voting consoles used purposefully and effectively; whether use is not only formal. The observation confirms that: ".. interactive whiteboards and voting consoles create maximum visibility of the use of formative assessment examples.. ", ".. feedback is immediate and personalized.. ", ".. technologies are used, focusing on goal.. ", ".. diversity of the questions.. ", ".. the voting system is very good to see the students understanding levels and weak points.. ", ".. the possibility of preventing the wrong answers before the colloquium.. ". Students in the focus group discussion said: ".. yes, it is better to make a mistake in lecture than colloquium.. ".

Lecturers together with their colleagues conducted an analysis of each observation, discussing what worked, what didn't, what is improvable. For example, some colleagues recommendations to the lecturer: ".. clarifying the objective at thebeginning of the class.. ", ".. clarify the terms in genetics.. ", ".. to clarify the formulation of several questions.. ". Several recommendations are consistent with the students' suggestions.

As a result of such organized pedagogical observation, a new refocusing was initiated at Rīga Stradinš University from visitation having more control function to lecturers' mutual cooperation and analysis of the experience. Thus, the main 
emphasis are: exchange of experience, discussion of different pedagogical solutions, including questions on the formative assessment, for example, differences in the methods according to the specifics of the study course, what is their justification, as well as being searched for solutions to similar problems.

\section{Conclusions}

In general, the following conclusions about formative assessment basic framework are drawn at Rīga Stradiņš University: clearly defined and measurable learning outcomes of study programs, study courses, lectures, seminars, practical workshops;

creation and provision of supportive and promotive learning environment. Organization of such environment, where there is no fear of making mistakes neither for teachers, nor students. Appropriate learning resource availability and choice;

feedback for reflection. Such assessment information that helps move forward;

the main emphasis of lecturers professional development are: exchange of experience, discussion of different pedagogical solutions, including questions on the formative assessment, for example, differences in the methods according to the specifics of the study course, what is their justification, as well as being searched for solutions to similar Problems;

formative assessment is organized purposefully and student involvement occurs essentially, then self reflection and communication are all important features of a student's employability and will be invaluable to them throughout their lives; one of the future directions of university should be change of the accent, not only in understanding of the need for formative assessment in everyday work, but to a much wider definition: formative approach at a class level to quality assessment at a institutional level. Thus, the major change envisages activation of formative approaches in pedagogical and administrative procedures at the institution as a whole.

\section{References}

[1] Black, P. (2003). The Nature and Value of Formative Assessment for Learning. Improving Schools, 6(7), 7-22.

[2] Black, P., Harrison, C., Lee, C., Marshall, B., \& Wiliam, D. (2003). Assessment for Learning: Putting it into practice. Maidenhead: Open University Press.

[3] Black, P., \& Wiliam, D. (2009). Developing The Theory of Formative Assessment. Educational Assessment, Evaluation and Accountability, 1(1), 5-31.

[4] Bloxham, S., \& Boyd, P. (2007). Developing effective assessment in higher Education a practical guide. Maidenhead: Open University Press.

[5] Clark, I. (2014). Equitable learning outcomes: Supporting economically and culturally disadvantaged students in 'formative learning environments'. Improving Schools, 17(1), 116-126

[6] Ecclestone, K., \& Davies, J. (2010). Transforming formative assessment in lifelong learning. Berkshire, England: Open University Press.

[7] Frey, N., \& Fisher, D. (2011). Feedback and Feed Forward: Giving Specific, Constructive Feedback to Individual Students Yields Deeper Understanding, and Using Student Data to Look for Patterns Across Students Allows Teachers to Make Good Instructional Decisions. Principal Leadership, 11(9), 90-93.

[8] Furtak, E. M., Kiemer, K., Circi, R. K., Swanson, R., de Leon, V., Morrison, D., \& Heredia, S. C, 2016). Teachers' formative assessment abilities and their relationship to student learning: findings from a four-year intervention study. Instructional Science, 44, 267-291.

[9] Hattie, J. (2009). Visible learning: A synthesis of over 800 meta-analyses relating to achievement. London: Routledge.

[10] McConnell, K. D., \& Doolittle, P. E. (2011). Classroom-Level Assessment: Aligning Pedagogical Practices to Enhance Student Learning. In: Secolsky, C., Denison, D. B. (Eds. ), Handbook on Measurement, Assessment, and Evaluation in Higher Education (pp. 15-30). Routledge. 
[11] Nicol, D. J., \& Macfarlane-Dick, D. (2006). Formative assessment and self-regulated learning: A model and seven principles of good feedback practice. Studies in Higher Education, 31(2), 199-218.

[12] Nicol, D. J., \& Milligan, C. (2006). Rethinking technology-supported assessment in terms of the seven principles of good feedback practice. In C. Bryan and K. Clegg (Eds), Innovative Assessment in Higher Education, Taylor and Francis Group Ltd, London.

[13] Sadler, D. R. (1998). Formative assessment: Revisiting the territory. Assessment in Education, 5(1), 77-84.

[14] Sambell, K. (2011). Rethinking feedback in higher education: an assessment for learning perspective. Bristol: ESCalate.

[15] Yorke, M. (2003). Formative assessment in higher education: Moves towards theory and the enhancement of pedagogic practice. Higher Education, 45(4), 477-501.

[16] Wheatley, L., Mclnch, A., Fleming, S., \& Lord, R. (2015). Feeding Back to Feed Forward: Formative Assessment as a Platform for Effective Learning. Kentucky Journal of Higher Education Policy and Practice, 3(2). 